Aftershock Characteristics as a Means of Discriminating Explosions from

Earthquakes

S. R. Ford, W. R. Walter

May 21, 2009

Bulletin of the Seismological Society of America 
This document was prepared as an account of work sponsored by an agency of the United States government. Neither the United States government nor Lawrence Livermore National Security, LLC, nor any of their employees makes any warranty, expressed or implied, or assumes any legal liability or responsibility for the accuracy, completeness, or usefulness of any information, apparatus, product, or process disclosed, or represents that its use would not infringe privately owned rights. Reference herein to any specific commercial product, process, or service by trade name, trademark, manufacturer, or otherwise does not necessarily constitute or imply its endorsement, recommendation, or favoring by the United States government or Lawrence Livermore National Security, LLC. The views and opinions of authors expressed herein do not necessarily state or reflect those of the United States government or Lawrence Livermore National Security, LLC, and shall not be used for advertising or product endorsement purposes. 


\title{
Aftershock Characteristics as a Means of Discriminating Explosions from Earthquakes
}

\author{
Sean R. Ford* and William R. Walter \\ Lawrence Livermore National Laboratory, Livermore, California, 94550, USA \\ *corresponding author: sean@1lnl.gov
}

\begin{abstract}
The behavior of aftershock sequences around the Nevada Test Site in the southern Great Basin is characterized as a potential discriminant between explosions and earthquakes. The aftershock model designed by Reasenberg and Jones $(1989,1994)$ allows for a probabilistic statement of earthquake-like aftershock behavior at any time after the mainshock. We use this model to define two types of aftershock discriminants. The first defines $M_{X}$, or the minimum magnitude of an aftershock expected within a given duration after the mainshock with probability $X$. Of the 67 earthquakes with $M>4$ in the study region, 63 of them produce an aftershock greater than $M_{99}$ within the first seven days after a mainshock. This is contrasted with only six of 93 explosions with $\mathrm{M}>4$ that produce an aftershock greater than $M_{99}$ for the same period. If the aftershock magnitude threshold is lowered and the $M_{90}$ criteria is used, then no explosions produce an aftershock greater than $M_{90}$ for durations that end more than 17 days after the mainshock. The other discriminant defines $N_{X}$, or the minimum cumulative number of aftershocks expected for given time after the mainshock with probability $X$. Similar to the aftershock magnitude discriminant, five earthquakes do not produce more aftershocks than $N_{99}$ within 7 days after the mainshock. However, within the same period all but one explosion produce less aftershocks then $N_{99}$. One explosion is added if the duration is shortened to two days after than mainshock. The cumulative number aftershock discriminant is more reliable, especially at short durations, but requires a low magnitude of completeness for the given earthquake catalog. These results at NTS are quite promising and should be evaluated at other nuclear test sites to understand the effects of differences in the geologic setting and nuclear testing practices on its performance.
\end{abstract}

\section{Introduction}

In a simple dislocation model of an earthquake, the mainshock occurs in response to the regional tectonic stress through slip along a fault. That slip produces regions of increased (and decreased) stress around the fault on which it occurred. These regions contribute to the temporal and spatial distribution of aftershocks. Explosions and other events that do not occur due to pre-existing stress along a fault, will have a different residual stress field, and therefore should have different aftershock distributions. This study aims to empirically quantify those differences in aftershock behavior and develop a new explosion discriminant based on them.

Over the years a variety of seismic techniques have been developed to discriminate explosions from earthquakes for many purposes ranging from removing industrial explosions from earthquake-only hazard catalogs to verifying international agreements such as the Comprehensive nuclear-Test-Ban Treaty (CTBT). Often these techniques depend upon ratios of 
seismic amplitudes such as the difference between the surface wave magnitude, Ms and the body-wave magnitude, mb (e.g. Stevens and Day, 1985) or the ratio of high frequency amplitudes of P-waves to S-waves (e.g. Walter et al., 1995, Hartse et al. 1997). However, these standard techniques can be limited by the available signal level. For example for small explosions the surface wave amplitudes can be below the noise level for the available stations such that Ms-mb cannot be used. In other cases the S-waves can be blocked or attenuated below detection level such that $\mathrm{P} / \mathrm{S}$ amplitude discriminant measures cannot be used. After the occurrence of a suspected explosion, additional instruments might be deployed and the behavior of any detected aftershocks could be useful to resolving the nature of the original event. Upon entry into force the CTBT allows for protocol that could lead to on-site inspections to help resolve the nature of a suspicious event. For these reasons the development of a quantitative method to discriminate between earthquake and explosion aftershock behavior would be useful.

There is a large body of literature devoted to understanding the behavior of earthquake aftershock sequences (for a review see Utsu et al. (1995); for an outstanding reference list see Shcherbakov et al. (2005)), but there are few studies of aftershocks due to explosions (e.g., Engdahl (1972), Hamilton and Healy (1969), Stauder (1971)). Ryall and Savage (1969) studied the aftershocks of the Nevada Test Site (NTS) nuclear test, BOXCAR, and found that the b-value in the Gutenberg-Richter relationship was smaller than for other Nevada earthquakes, but that the aftershock decay was similar. Hamilton et al. (1972) looked at four tests including the very well studied BENHAM (see Bull. Seis. Soc. Amer. special issue vol. 59 no. 6) explosion and found that the tests produced fewer large magnitude aftershocks than comparable earthquakes in the region. Adushkin et al. (1995) studied explosion aftershock sequences at Russian test sites and found variable aftershock activity decay rates that they related to local geology and hydrology. Gross (1996) investigated the differences between explosion and earthquake aftershocks to see if the seismicity rate in the Yucca Mountain region could be due to transient stress perturbations from past nuclear tests. She found a best model of aftershock decay for each explosion and compared those model parameters with a previous study of earthquake aftershocks in the region. One of her conclusions was that aftershocks from explosions decay at a greater rate than those from earthquakes, but that this could be due to a depth effect described by Dieterich (1994) and not related to the source-type. Jarpe et al. (1994) compared nuclear test explosions with the NonProliferation Experiment (NPE) chemical explosion and found that the aftershock behavior was similar for all explosions, but that explosions produced aftershocks with smaller magnitude relative to earthquakes. Finally, Ringdal et al. (1999) noted that a small aftershock of the 1997 Kara Sea event provided added confidence that the event was an earthquake.

We are motivated by these observations, especially those of Jarpe et al. (1994), to produce an explosion discriminant based on the quantitative comparison of the aftershocks of earthquakes and explosions. The probabilistic aftershock rate model of Reasenberg and Jones $(1989 ; 1994)$ and Gerstenberger et al. (2005) provide the perfect tool to make such a discriminant. The model calculates the probability of an aftershock greater than magnitude $M$ at a given time $t$ after the mainshock with magnitude $\mathrm{Mm}$. It begins with a stochastic model for the aftershock rate given by

$$
\lambda(t)=\frac{10^{a+b(M m-M)}}{(t+c)^{p}} .
$$


This relationship comes from combining the modified Omori law that describes the number of aftershocks at a given time

$$
N(t)=\frac{K}{(t+c)^{p}},
$$

where $K, c$, and $p$ are constants ( $K$ is related to the productivity and $p$ to its decay), with the Gutenberg-Richter relationship that describes the number of aftershocks for a given magnitude

$$
N(M)=A 10^{-b M},
$$

where $b$ parameterizes the ratio of small to large events (Gerstenberger et al., 2004). The parameters in eqs (2) and (3) are found by fitting the models in a maximum-likelihood sense to frequency and magnitude distributions from a given aftershock sequence (AS). In equation (1) $a$ is proportional to the productivity of a volume, or the seismicity rate (Wiemer, 2000) and is given by

$$
a=\log _{10}(K)-b(M m-M m i n)
$$

(Gasperini and Lolli, 2006), where Mmin is the smallest recorded event in the aftershock sequence. When Mmin is less than the magnitude of completeness $M c$ for a given catalog, the number of aftershocks with magnitude between those two values may be underestimated and a correction must be applied based on assumptions of the magnitude distribution for the aftershock sequence (Lolli and Gasperini, 2003). Therefore, in order to simplify the analysis we only look at events greater than $M c$ to define the aftershock distribution. The aftershock parameters ( $b, p, c$, and $a$ ) calculated by Reasenberg and Jones (1989) and used by the real-time hazard analysis of USGS (Gerstenberger et al., 2005) are in Table 1 (SoCal parameters).

Assuming a non-homogeneous Poissonian occurrence of aftershocks, the probability of $n$ events occurring above magnitude $M$ within an interval $(0, t)$ is

$$
p(n, t)=\frac{\left(\int_{0}^{t} \lambda(t) d t\right)^{n}}{n !} \exp \left[-\int_{0}^{t} \lambda(t) d t\right]
$$

(Papoulis, 1965; Reasenberg, 1985), and the case of at least one event greater than $M$ within a given observation period is one minus the probability of zero events, or

$$
P=1-\exp \left[-\int_{S}^{T} \lambda(t) d t\right]
$$

(Reasenberg and Jones, 1994), where $S$ and $T$ are the initial and final time of the observation period, respectively. For example, using the SoCal parameters (Table 1) in eqn (5) gives a 
probability of 0.402 that an aftershock with $M \geq M m-1$ will occur between 1 and 30 days $(S=1, T$ =30) after the mainshock. Lolli \& Gasperini (2006) show that error is reduced if the aftershock parameters are calculated from aftershock populations that begin one day after the mainshock $(S$ $=1$ ), and when this is done the best choice of $c$ is 0 . We will follow their suggestion in this study.

The goal of this study is to find the aftershock magnitude that has a high probability, $\mathrm{P}=X$, of occurring at any time after the mainshock. We can denote this magnitude as $M_{X}$, so for example an aftershock magnitude that will occur with a probability of $\mathrm{P}=0.95$ within a given time period is $M_{95}$. If the aftershock population does not contain an event greater than $M_{X}$ than the sequence is anomalous and could be characterized as an explosion. We can also find the cumulative number of aftershocks above the $M c$ of the catalog at a given probability for a given time. If the aftershock sequence has less than this number of cumulative events, the sequence can also be characterized as anomalous. One advantage to this approach is that a determination of an anomalous sequence can be made at any time and at any probability. We test the method using the explosion and earthquake seismicity in the NTS region.

\section{Data and Method}

The first step is to find the aftershock parameters for earthquake aftershock sequences in the NTS region (Figure 1). This study will use the extensive dataset of seismicity in the southern Great Basin that was produced for the Yucca Mountain seismic hazard study (Stepp et al., 2001, see Data and Resources section). The seismic network in the region was greatly improved beginning in 1968, so we will begin at this time and end a year after the last nuclear test in Sep 92, where we are sure to include the unusually shallow Rock Valley and normal depth Eureka Valley sequences which occurred on 30 and 17 May 93, respectively. This is also the approximate time when the University of Nevada, Reno (UNR) took over monitoring of the region and the catalog changed greatly. The period from 1968 to 1978, and from 1978 to 1992 has an approximate $M c$ of 2.5 and 1.5, respectively (von Seggern and Brune, 2000), so these values are used in the analysis. The nuclear test catalog is taken from Springer et al. (2002) and the aftershock search is constrained to the region defined by UNR as the southern Great Basin where the earthquake catalog is most complete. We assume that an aftershock sequence in this region is in a similar tectonic regime as that at the NTS. The study region is shown with a white box in Figure 1.

Lolli \& Gasperini (2003) showed that declustering with a sophisticated algorithm like CLUSTER2000x (Reasenberg, 1985) gave similar results to declustering using a simple spacetime criteria. We use a search radius and time period defined by Uhrhammer (1986), which was also used by Wiemer and Schorlemmer (2007) to decluster a California catalog. As a conservative measure we add 60 days and $15 \mathrm{~km}$ to the distance and time given by the Uhrhammer (1986) relations so that search radius is

$$
r=15+\exp (-1.024+0.804 \mathrm{Mm}),
$$

and the time window is 


$$
t_{\text {win }}=60+\exp (-2.87+1.235 \mathrm{Mm}) \text {. }
$$

Based on these criteria a M4.3 event requires a search radius and time window of about $26.4 \mathrm{~km}$ and 71.5 days, respectively, and a M6 event needs a radius of $59.7 \mathrm{~km}$ and time window of 153.7 days. We find seven clusters that have $M m>4$ and more than 40 events above $M c$. A minimum number of 40 events is chosen so as to produce robust estimates of the model parameters. The clustering method does not prohibit sequences from overlapping in time or space, however the seven clusters that met the criteria $(M m>4$ and $\mathrm{N}>40)$ did not overlap in both time and space. For completeness $M c$ was estimated from the aftershock sequence by computing the maximum value of the first derivative of the frequency-magnitude curve (maximum curvature method of Wiemer and Wyss, 2000). If the Mc was above that given by von Seggern and Brune (2000) for the specified period in which the mainshock occurred then we used the aftershock-derived $M c$ instead. The modified Omori-law parameters in eq (2) are estimated with the maximumlikelihood method of Ogata (1983) (as described in Ogata, 1999). The b-value in the GutenbergRichter relationship (eq (3)) is calculated with the maximum-likelihood method of Aki (1965) (as described by Shi and Bolt, 1982). Aftershock parameters for the seven clusters and their median values are given in Table 1. Figure 2 show the maximum-likelihood fits to the models for the Little Skull Mt. (LSM) sequence. The b-value $(b=0.83)$ agrees well with von Seggern et al. (2003) $(b=0.82)$, though $p(p=0.78)$ is very different than was found by Gross (1996) $(p=$ 1.08). The difference may be due to the Mmin used in the distribution. If the lowest $M$ recorded is used, $p$ is increased to slightly more than 1 . However, we feel the choice of Mmin that coincides with the $M c$ is more appropriate in that aftershocks below $M c$ may not be fully recorded.

Aftershock rates and probabilities for an aftershock of magnitude $M \geq M m$-1 are given for each sequence in Figure 3. For example, the probability that an aftershock of magnitude 4.6 will occur 30 days after the LSM mainshock is 0.904 . All models produce an aftershock rate that is greater than the median models of previous studies of Southern California (Reasenberg and Jones, 1989), Italy (Lolli and Gasperini, 2003), and New Zealand (Eberhart-Philips, 1998). Though, some of these studies used more sophisticated windowing procedures that better eliminated background seismicity for the analysis. However, it should be noted that a small minority of the sequences measured in those studies have rates similar to those measured here. As was done in the previous studies of Southern California, Italy and New Zealand, we will use the median model to calculate aftershock probabilities for the region, and in a later section we will show that discriminatory capability is dependent on an appropriate model for the region.

\section{Aftershock magnitude discriminant}

With the median model aftershock parameters we can now define $M_{X}$, or the minimum differential aftershock magnitude (mainshock magnitude, $M m$, minus aftershock magnitude, $M$ ) that has a probability $\mathrm{P}=X$ of occurring between one day after the mainshock and time $t(S=1, T$

$=t$ ). First, we calculate the probability for all differential aftershock magnitudes, $d M(M m-M)$ in Figure 4. Curves for a given probability $\mathrm{P}=X$ now define $M_{X}$ for each duration ending at time $t$, and are given by evaluating the definite integral of eq (6), where $S=1$, rearranging, and taking $c$ $=0$ to find 


$$
M_{X}=\frac{1}{b} \log _{10}\left[-\ln (1-X) \frac{10^{-a}(1-p)}{T^{(1-p)}-1}\right]
$$

For example, using the median model parameters, after 7 days $99 \%$ of aftershock sequences will have an event greater than the mainshock magnitude minus 1.82 magnitude units $(d M \leq 1.82)$. Figure 5a applies this example to the LSM sequence $(M m=5.6)$. In this case, we would expect at least one aftershock where $M \geq 3.78$ less than 7 days after the mainshock (gray region in Figure 5a). In fact, within this period there were three events greater than 3.8 including an M4.4 six days later (Smith et al., 2001).

There are $67 \mathrm{M}>4$ events that have an aftershock region completely within the study region. For each of the 67 events we define an aftershock region in space and time by eqns (6) and (7) and examine the aftershocks in that region. The simplistic spatio-temporal aftershock region definition, where no attempt is made at further declustering or elimination of background seismicity, is informed by design considerations of a realistic discriminatory monitoring regime, which should be causal and preferably simple. Table 2 gives the results for these events. Within one week, 63 earthquakes in the dataset (94.0\%) produced an aftershock greater than $M_{99}$, and within 30 days $79.0 \%$ of the earthquakes produced an aftershock greater than $M_{90}$. Based on the probabilities, one would expect that within one week three more events (66 instead of 63 of 67) would have produced an aftershock greater than $M_{99}$, and that after 30 days, seven more events (60 of 67) would have produced an aftershock greater than $M_{90}$. The differences from the model may be due to several causes. Natural variation in aftershock sequences is evident in Figure 2, and a median parameterization does not reflect that variation. The clustering method is very simplistic, and no attempt at excluding background seismicity is made. Finally, the Reasenberg and Jones (1989) model was chosen for its simplicity, and it may not accurately reflect the complexity in earthquake aftershock sequences.

The locations of the four non-explosion events that did not produce an $M_{99}$ within 7 days of the mainshock and the search radius used to define the aftershock region are shown in Figure 1 and listed in Table 3. Two of the anomalous events are at the NTS, and one of them (24 Mar 70) coincides with the location and time given for the collapse following the nuclear test SHAPER (Springer et al., 2002). The relatively rapid collapse of an explosion-generated cavity to form a surface crater can generate a seismic signal, which we believe is what occurred in this case. While the seismicity catalog appears to have been purged of most of the post-shot collapses documented in Springer et al. (2002), this one was missed.

Explosion aftershock distributions are defined for all explosions with a recorded $M>4$. The spatial extent of the search zone is the same as described before, but the end of the time window is taken as the smaller of either the time described by eq (7) or the event time of the next explosion. This was done so that aftershocks could be easily identified with a given explosion. These criteria result in 121 explosions with time windows greater than 1 day (81 explosions had durations less than one day). Figure 5b shows the results for the BENHAM test on 19 Dec 68 (M6.4). The largest aftershock was two days after the test and was a M4.7 event $(M m-M=1.7)$. One would expect an aftershock of this size within 3.7, 5.2, and 10.7 days of the mainshock at probabilities of $0.90,0.95$, and 0.99 , respectively. However, for durations greater than 3.7, 5.2, and 10.7 days only $10 \%, 5 \%$, and $1 \%$ of aftershock sequences do not produce an event greater 
than M4.7, respectively. After these times one can consider this aftershock sequence anomalous within the given probability threshold. Figure 5c shows the results for all 121 explosion aftershock sequences. Due to the time window criteria discussed previously not all of the sequences have the same duration, and the actual number of sequences as a function of duration is also plotted. For a duration of 17 days, there is a $90 \%$ probability that there will have been an aftershock within the gray region defined in Figure 5c. But, for durations greater than 17 days no explosions produced an aftershock greater than $M_{90}$.

In order to better compare with the earthquake analysis, Table 4 gives results for explosions that had a time window greater than the duration analyzed. Within a week only 6 of 93 explosions (6.5\%) produced an aftershock greater than $M_{99}$. The locations of these six explosions and the search radius used to define the aftershock region are shown in Figure 1 and listed in Table 5. Five of the six events occurred at the Pahute Mesa section of the NTS (Springer et al., 2002). All of them took place early in the catalog (1968-1976). Of the 36 explosions with aftershock windows greater than 30 days, none produced an $M_{99}$ aftershock. Of course, in a real-world scenario the nuclear test times would be unknown and the observation durations could not be specified as they are here. In this case, a subsequent nuclear test occurring within days of an initial test would be interpreted as an aftershock, and if its magnitude were great enough, the 'sequence' would appear earthquake-like.

\section{Aftershock number discriminant}

The aftershock magnitude discriminant finds the magnitude at which we would expect at least one aftershock for a given duration after the mainshock. If the aftershock detection magnitude threshold $(M c)$ is low enough, another approach to an aftershock discriminant is the number of observed aftershocks for a given duration. We employ eq (5) to calculate $N_{\mathrm{X}}$, the minimum number of expected aftershocks with probability $X$ for a given duration since the mainshock. First, the probability of observing more than $N$ events within a duration beginning one day after the mainshock and time $T$ is found by evaluating the definite integrals of eq (5) from 1 day to time $T$, rearranging, taking $c=0$, and summing to get

$$
P=1-\sum_{0}^{N} \frac{1}{n !}\left[10^{a+b d M} \frac{1-T^{1-p}}{1-p}\right]^{n} \exp \left[-10^{a+b d M} \frac{1-T^{1-p}}{1-p}\right]
$$

In the case of the aftershock magnitude discriminant, $N$ is unity and the difference between the mainshock magnitude $(\mathrm{Mm})$ and aftershock magnitude $(M)$ was calculated $(d M=M m-M)$. For the aftershock number discriminant, we fix $d M$ where the aftershock magnitude is set to magnitude detection threshold $(d M=M m-M c)$ and calculate $N$ for a given probability $X$. The finite factorial sum in eq (10) has no definite solution and $N_{X}$ must be solved numerically. Figure 6 shows the calculation of $N_{X}$, where $X=0.90,0.95$, and 0.99 , for the case of LSM, where $M m=$ 5.6 and $M c=1.5(d M=4.1)$. For the example given in Figure $6 a$, there is a $99 \%$ probability that at least 343 cumulative aftershocks with $M \geq 1.5$ have occurred within 7 days of the mainshock.

Figure 7 shows the performance of this type of aftershock discriminant with data from LSM and BENHAM. At no time does the LSM sequence produce less aftershocks than is expected at $\mathrm{p}=0.99$ and BENHAM performs similarly, which is to say, earthquake-like. We examine the 
same earthquake and explosion aftershock sequences as for the aftershock magnitude discriminant and find where the events produce anomalous aftershock numbers. The earthquake results are summarized in Table 6 . Two of the five earthquakes that did not produce more aftershocks than $N_{99}$ within seven days are the same as those from Table 2 (30 Jul 70 and 6 Jul 82). Figure 8a gives the anomalous aftershock sequence of one of the other three events (20 Dec 91, M4.1). Interestingly, the only anomalous explosion at the durations of 7 and 14 days is BENHAM. In fact, when the duration is shortened to only two days after the mainshock, just one more explosion (PONL, 27 Sep 85) exhibits earthquake-like aftershock activity. The aftershock sequence of PONL is given in Figure $8 \mathrm{~b}$. This is in contrast to the aftershock magnitude discriminant, which for a duration of 2 days characterizes 7 explosions (5.8\%) as earthquake-like $(p=0.99)$.

\section{Method comparison}

We compare the performance of the two types of aftershock discriminants by calculating the percentage of false classifications for earthquakes and explosions as a function of observations duration since the mainshock for both types of discriminants at the $99 \%$ and $90 \%$ probabilities. Figure 9a shows the percent of explosions classified as earthquake-like. The aftershock magnitude discriminant $\left(M_{99}\right.$ and $\left.M_{90}\right)$ does not perform as well as the aftershock number discriminant ( $N_{99}$ and $N_{90}$ ) with durations less than about 2 weeks. This is due to a few explosion aftershock sequences that have one large event early on, but that event is not larger than would be expected in a sequence lasting more than 2 weeks. The percent misclassified for both discriminants is comparable to previous studies for the NTS using other discriminants (Taylor et al., 1989). Figure 9b shows the percent of earthquakes classified as anomalous. For a duration of one day, the magnitude discriminant does not perform well. However, for durations greater than one day and less than 17 days, both discriminants perform equally as well. The $M_{90}$ discriminant performs poorly for durations greater than 17 days, suggesting that after this time there are several earthquake aftershock sequences that do not produce an aftershock that is as large as expected at the $90 \%$ probability. The discriminant that produces the fewest misclassifications of both types is the $N_{90}$ discriminant, though with the trade-off that it misses the most earthquakes for durations less than 16 days.

As an additional test to show that a regional parameterization is required, we compare the previous results with those obtained using the SoCal model (Table 1). Since the SoCal model predicts fewer and smaller aftershocks than the Median model (as shown in Figures 2), more earthquake aftershock sequences are consistent with it. This effect on the magnitude discriminant can be seen in Figure 5c and listed in Table 2, where for a probability of 99\% there are 4 and 2 additional sequences consistent with the model for durations of 7 and 14 days, respectively. However, the decrease in predicted magnitude also means that more explosion aftershocks are consistent with the model, and Table 4 shows that for a duration of 7 days more than $87 \%$ of explosion aftershock sequences look earthquake-like. The same is true for the number discriminant as shown in Figure $6 \mathrm{~b}$ and listed in Tables 6 and 7, where after 30 days all explosion sequences look earthquake-like. Figure 9 incorporates the SoCal results for comparison with the Median model at all durations. Though the SoCal model misclassifies fewer earthquake sequences, the increased explosion misclassification (not even visible with the axes 
of Figure 9a) demonstrates the need for a regional parameterization to produce a discriminant capability.

\section{Independent case study}

We test the robustness of the result with an out-of-sample case study of the $\mathrm{M}_{\mathrm{L}} 5.3$ earthquake that occurred at Scotty's Junction on 1 Aug 99. This event occurred a few tens of kilometers west of NTS at a later date then the catalogs we considered in the study. Within one week after the event, there was an M3.8 event, which made the sequence look earthquake-like at all probability levels (Figure 10a). For durations greater than 7.7 and 12.8 days the sequence was anomalous at probabilities of 90 and $95 \%$, respectively. However, the aftershock surpassed $M_{99}$ (the most conservative measurement) for durations less than $\sim 35$ days. The sequence looked earthquakelike for all durations when the aftershock number discriminant is used (Figure 10b). In this case the magnitude of completeness is 2 (estimated from the data as described above), which allows for a large number of events to be observed. Both these tests show that the event could be classified as an earthquake at $\mathrm{p}=0.99$. It should be noted that approximately 14 hours after the mainshock there was a M4.6 ( $d M 0.7)$ aftershock. Since, we begin observation one day after the mainshock, the large aftershock was not considered in the discriminant analysis. Future work will test sequence completeness for small durations so that the one day delay threshold can be relaxed to take advantage of a sequence like Scotty's Junction that produces a large aftershock less than 24 hours after the mainshock.

\section{Conclusions}

The behavior of aftershock sequences in the southern Great Basin has been characterized in order to investigate anomalous aftershock sequences. A thorough analysis of the aftershock model parameters is beyond the scope of this study, rather it is our goal to show that a given model can discriminate earthquake aftershocks from explosion aftershocks. The model designed by Reasenberg and Jones $(1989,1994)$ allows for a probabilistic statement of earthquake-like aftershock behavior at any time after the mainshock. We use this model to create two aftershock discriminants. The first defines $M_{\mathrm{X}}$ or the minimum magnitude of an aftershock expected within a given duration after the mainshock with probability $\mathrm{X}$. Of the 67 earthquakes with $\mathrm{M}>4$ in our study region, 63 of them produce an aftershock greater than $M_{99}$ within the first seven days after a mainshock. This is contrasted with the 6 out of 93 explosions with $M>4$ that produce an aftershock greater than $M_{99}$ for the same period. If the aftershock magnitude threshold is lowered and the $M_{90}$ criteria is used, then no explosions produce an aftershock greater than $M_{90}$ within 17 days of the mainshock.

The other discriminant defines $N_{\mathrm{X}}$ or the minimum cumulative number of aftershocks expected for a given duration after the mainshock with probability $\mathrm{X}$. This aftershock number discriminant has similar performance in the analysis of earthquakes, but only classifies one explosion aftershock sequence as earthquake-like for $\mathrm{p}=0.99$ within 7 days after the mainshock. The number increases to two when the duration is shortened to two days. This is the preferred aftershock discriminant when the $M c$ of the catalog in the region is a few magnitude units less than the mainshock. 
As an earthquake/explosion discriminant these NTS results are quite promising. To test its robustness in other tectonic regimes and nuclear test sites with different emplacement conditions the $M c$ of the seismicity catalog in the region must be low enough to first characterize an aftershock model. For example to test the methodology in the Yellow Sea / Korean Peninsula region on the October $2006 \mathrm{mb} 4.2$ (PDE) North Korean explosion, requires a catalog with an $M c$ substantially smaller than the event. Unfortunately the $M c$ of the IDC and PDE catalogs in the region was a little less than 4 and the $M c$ of the ISC catalog in the same region is a little more than 4 (Woessner and Wiemer, 2005). Future application to a number of other test sites will first require building seismicity catalogs with lower $M c$ values through correlation (e.g. Gibbons and Ringdal, 2006) or other techniques.

\section{Data and Resources}

The earthquake catalog is from the Yucca Mountain seismic hazard study as compiled by Stepp et al. (2001) is available on CD-ROM as part of Walter et al. (2006). The University of Nevada Seismological Laboratory Earthquake Catalog was searched using http://www.seismo.unr.edu/Catalog/ (last accessed on 5 Apr 09). Some plots were made using the Generic Mapping Tools version 4.2.2 (www.soest.hawaii.edu/gmt; Wessel and Smith, 1998). Catalog analysis was done with ZMAP (www.earthquake.ethz.ch/software/zmap, Wiemer, 2001)

\section{Acknowledgements}

We are very indebted to the authors of ZMAP (Wiemer, 2001). We are grateful for an internal review by Jerry Sweeney, and a very helpful formal review by Max Werner and an anonymous reviewer. We thank Terri Hauk who loaded the catalog and Stan Rupert for overseeing the LLNL seismic computational infrastructure. This work was performed under the auspices of the Lawrence Scholar Program and the U.S. Department of Energy by Lawrence Livermore National Laboratory under Contract DE-AC52-07NA27344. This is LLNL contribution LLNL-JRNL408460. 


\section{References}

Adushkin, V., and A. Spivak (1995). Aftershock of Underground Nuclear Explosion, in Earthquakes Induced by Underground Nuclear Explosions: Environmental and Ecological Problems (Nato Asi Series. Series 2, Environment, Vol 4) ed. R. Console and A. Nikolaev., 35-49.

Aki, K. (1965). Maximum likelihood estimate of $b$ in the formula $\log N=a-b M$ and its confidence limits, Bull. Earthquake Res. Inst., Tokyo Univ. 43, 237-239.

Aki, K., P. Reasenberg, T. Defazio, and Y. B. Tsai (1969). Near-Field and Far-Field Seismic Evidences for Triggering of an Earthquake by Benham Explosion, Bulletin of the Seismological Society of America 59, 2197-\&.

Bucknam, R. C. (1969). Geologic Effects of Benham Underground Nuclear Explosion, Nevada Test Site, Bulletin of the Seismological Society of America 59, 2209-\&.

Crowley, B. K., and L. S. Germain (1971). Energy Released in Benham Aftershocks, Bulletin of the Seismological Society of America 61, 1293-\&.

Dieterich, J. (1994). A Constitutive Law for Rate of Earthquake Production and its Applications to Earthquake Clustering, Journal of Geophysical Research, 99 (B2), 2601-2618.

Eberhart-Phillips, D. (1998). Aftershock sequence parameters in New Zealand, Bull. Seism. Soc. Amer., 88 (4), 1095-1097.

Engdahl, E. R. (1972). Seismic effects of the Milrow and Cannikin Nuclear Explosions; Cannikin Nuclear Explosion, Bulletin of the Seismological Society of America 62, 14111423.

Gasperini, P. and B. Lolli (2006). Correlation between the parameters of the aftershock rate equation: Implications for the forecasting of future sequences, Physics of the Earth and Planetary Interiors, 156, 41-58.

Gerstenberger, M. C., S. Wiemer, and L. M. Jones (2004). Real-time forecasts of tomorrow's earthquakes in California: A new mapping tool, U.S. Geological Survey Open-File Report 2004-1390.

Gerstenberger, M. C., S. Wiemer, L. M. Jones, and P. A. Reasenberg (2005). Real-time forecasts of tomorrow's earthquakes in California, Nature (London) 435, 328-331.

Gibbons, S. J. and F. Ringdal (2006). The detection of low magnitude seismic events using array-based waveform correlation, Geophys. J. Int. 165, 149-166.

Gross, S. (1996). Aftershocks of nuclear explosions compared to natural aftershocks, Bulletin of the Seismological Society of America 86, 1054-1060. 
Hamilton, R. M., and J. H. Healy (1969). Aftershocks of Benham Nuclear Explosion, Bulletin of the Seismological Society of America 59, 2271-\&.

Hamilton, R. M., F. A. Mckeown, and J. H. Healy (1969). Seismic Activity and Faulting Associated with a Large Underground Nuclear Explosion, Science 166, 601-\&.

H. Hartse S. R. Taylor, W. S. Phillips, and G. E. Randall, (1997). A preliminary study of regional seismic discrimination in Central Asia with an emphasis on Western China, Bull. Seism. Soc. Am. 87, 551-568.

Jarpe, S, Goldstein, P, Zucca, J J (1994). Comparison of the non-proliferation event aftershocks with other Nevada Test Site events, UCRL-JC-117754.

Lolli, B. and P. Gasperini (2003). Aftershocks hazard in Italy Part I: Estimation of timemagnitude distribution model parameters and computation of probabilities of occurrence, Journal of Seismology, 7, 235-257.

Ogata, Y. (1983). Estimation of the parameters in the modified Omori formula for aftershock frequencies by the maximum-likelihood procedure, J. Phys. Earth, 31 (2), 115-124.

Ogata, Y. 1999. Seismicity analysis through point-process modeling: A review. Pure and Applied Geophysics, 155 (2-4), 471-507.

Papoulis, A. (1965). Probability, Random Variables, and Stochastic Processes, McGraw-Hill, San Francsico.

Reasenberg, P. A., and L. M. Jones (1994). Earthquake Aftershocks - Update, Science 265, 1251-1252.

Reasenberg, P. A., and L. M. Jones (1990). California Aftershock Hazard Forecasts, Science $247,345-346$.

Reasenberg, P. A., and L. M. Jones (1989). Earthquake Hazard After a Mainshock in California, Science 243, 1173-1176.

Reasenberg, P. A., and M. V. Matthews (1990). California Aftershock Model Uncertainties Response, Science 247, 343-345.

Reasenberg, P. A. (1985). Second-order moment of Central California seismicity, 1969-1982, Journal of Geophysical Research 90, 5479-5495.

Ringdal, F., E. Kremenetskaya, V. Asming, T. Kvaerna, and J. Schweitzer (1999). Research in Regional Seismic Monitoring, in 21st Seismic Research Symposium, Las Vegas, USA. Published by Los Alamos National Laboratory - LA-UR-99-4700.

Ryall, A., and W. U. Savage (1969). A comparison of seismological effects for the Nevada underground test Boxcar with natural earthquakes in the Nevada region, Journal of Geophysical Research 74, 4281-4289. 
Shcherbakov, R., D. L. Turcotte, and J. B. Rundle (2005). Aftershock statistics, Pure and Applied Geophysics, 162, 1051-1076.

Shi, Y., and B. A. Bolt (1982). The standard error of the magnitude-frequency b value, Bull. Seism. Soc. Am. 72,1677 -1687.

Smith, K. D., J. N. Brune, D. de Polo, M. K. Savage, R. Anooshehpoor, and A. F. Sheeham (2001). The 1992 Little Skull Mountain earthquake sequence, southern Nevada Test Site, Bulletin of the Seismological Society of America 91, 1595-1606.

Springer, D. L., G. A. Pawloski, J. L. Ricca, R. F. Rohrer, and D. K. Smith (2002). Seismic source summary for all U.S. below-surface nuclear explosions, Bulletin of the Seismological Society of America 92, 1806-1840.

Stauder, W. (1971). Smaller Aftershocks of Benham Nuclear Explosion, Bulletin of the Seismological Society of America 61, 417-\&.

Stepp, J. C, I. Wong, J. Whitney, R. Quittemeyer, N. Abrahamson, N., G. Toro, R. Youngs, K. Coppersmith, J. Savy, T. Sullivan, and Yucca Mountain PSHA Project Members (2001). Probabilistic seismic hazard analyses for ground motions and fault displacements at Yucca Mountain, Nevada, Earthquake Spectra 17, 113-151.

Stevens, J. L. and S.M. Day, (1985). The physical basis of mb:Ms and variable frequency magnitude methods for earthquake/explosion discrimination, J. Geophys. Res., 90, 30093020.

Taylor, S. R., M. D. Denny, E. S. Vergino, and R. E. Glaser (1989). Regional discrimination between NTS explosions and Western U.S. earthquakes, Bulletin of the Seismological Society of America, 79 (4), 1142-1176.

Uhrhammer, R. (1986). Characteristics of northern and southern California seismicity. Earthquake Notes 57, 21.

Utsu, T., Ogata, Y., Matsuura, R. S. (1995). The centenary of the Omori formula for a decay law of aftershock activity, Journal of Physics of the Earth, 43, (1), 1-33.

von Seggern, David H., and J. N. Brune (2000). Seismicity in the Southern Great Basin, 18681992, in Geologic and geophysical characterization studies of Yucca Mountain, Nevada, J. W. Whitney, and W. R. Keefer (Editors), Vol. DDS-0058, United States (USA).

von Seggern, D. H., J. N. Brune, K. D. Smith, and A. Aburto (2003). Linearity of the earthquake recurrence curve to $\mathrm{M}<-1$ from Little Skull Mountain aftershocks in southern Nevada, Bulletin of the Seismological Society of America 93, 2493-2501.

Walter, W. R., K. Mayeda, and H. J. Patton, (1995). Phase and spectral ratio discrimination between NTS earthquakes and explosions, part I: empirical observations, Bull. Seism. Soc. Am. 85, 1050-1067. 
Walter, W. R., K. D. Smith, J. L. O’Boyle, T. F. Hauk, F. Ryall, S. D. Ruppert, S. C. Myers, R. Abbot, D. A. Dodge, (2006). An assembled western United States dataset for regional seismic analysis, Lawrence Livermore National Laboratory, UCRL-MI-222502. CRROM available upon request.

Wiemer, S. (2001), A software package to analyze seismicity: ZMAP, Seism. Res. Lett., 72, 373382.

Wiemer, S, and D. Schorlemmer (2007). ALM: An asperity-based likelihood model for California, Seism. Res. Lett., 78 (1): 134-140.

Wiemer, S., and M. Wyss (2000). Minimum magnitude of completeness in earthquake catalogs: Examples from Alaska, the Western United States, and Japan, Bull. Seis. Soc. Amer., 90 (4), 859-869.

Woessner, J. and S. Wiemer (2005) Assessing the Quality of Earthquake Catalogues: Estimating the Magnitude of Completeness and Its Uncertainty, Bulletin of the Seismological Society of America, 95 (2), 684-698, doi: 10.1785/0120040007. 
Table 1. Aftershock parameters

\begin{tabular}{lllllllll}
\hline ID (Abbreviation) & $\begin{array}{l}\text { Mainshock } \\
\text { YYMMDD }\end{array}$ & $\mathrm{Mm}^{1}$ & $\operatorname{Mmin}^{2}(\mathrm{~N})$ & $M c^{3}(\mathrm{~N})$ & $b$ & $p$ & $c$ & $a$ \\
\hline Eureka Valley (EV) & 930517 & 6.2 & $0.5(1178)$ & $1.9(718)$ & 0.74 & 1.06 & 0 & -0.96 \\
Little Skull Mt. (LSM) & 920629 & 5.6 & $0.5(2715)$ & $1.5(1552)$ & 0.83 & 0.78 & 0 & -1.11 \\
S3 & 821001 & 4.8 & $0.4(232)$ & $2.5(81)$ & 1.34 & 0.82 & 0 & -1.77 \\
S4 & 820307 & 4.7 & $0.7(249)$ & $1.5(64)$ & 0.70 & 0.61 & 0 & -1.22 \\
S5 & 920630 & 4.7 & $0.5(723)$ & $1.5(314)$ & 0.81 & 0.54 & 0 & -1.04 \\
S6 & 920520 & 4.5 & $0.4(445)$ & $1.5(107)$ & 0.88 & 0.82 & 0 & -1.27 \\
Rock Valley (RV) & 930530 & 4.3 & $0.8(84)$ & $1.5(46)$ & 0.89 & 1.05 & 0 & -1.27 \\
Median Model (Med) & & & & & 0.83 & 0.82 & 0 & -1.22 \\
SoCal $^{\mathrm{a}}$ & & & & & 0.91 & 1.08 & 0.05 & -1.67 \\
Italy $^{\mathrm{b}}$ & & & & & 0.98 & 0.92 & 0.09 & -1.84 \\
$\mathrm{NZ}^{\mathrm{c}}$ & & & & & 1.03 & 1.02 & 0.03 & -1.66 \\
\hline
\end{tabular}

${ }^{1}$ Mainshock magnitude

${ }^{2}$ Minimum magnitude in sequence

${ }^{3}$ Magnitude of completeness for sequence

${ }^{\mathrm{a}}$ Reasenberg and Jones, 1989

${ }^{\mathrm{b}}$ Lolli and Gasperini, 2003

${ }^{\mathrm{c}}$ Eberhart-Philips, 1998

Table 2. Number of earthquake aftershock sequences that produced an event greater than predicted at the given probability within the given duration (with $\%$ of total, $\mathrm{N}=67$ )

\begin{tabular}{llll}
\hline \multicolumn{3}{c}{ Duration } \\
Probability & 7 days & 14 days & 30 days \\
\hline 0.90 & $62(92.5 \%)$ & $59(88.1 \%)$ & $53(79.0 \%)$ \\
0.95 & $63(94.0 \%)$ & $60(89.6 \%)$ & $60(89.6 \%)$ \\
0.99 & $63(94.0 \%)$ & $63(94.0 \%)$ & $64(95.5 \%)$ \\
$0.99_{\text {SoCal }}$ & $67(100 \%)$ & $65(97.0 \%)$ & $64(95.5 \%)$ \\
\hline
\end{tabular}

Table 3. Four events that did not produce an $M_{99}$ aftershock within seven days

\begin{tabular}{lllllll}
\hline Lon & Lat & Mag & Year & Mon & Day & Time (UTC) \\
\hline-116.155 & 37.233 & 4.5 & 1970 & 3 & 24 & $01: 15$ \\
-116.560 & 37.283 & 4.4 & 1970 & 7 & 30 & $20: 16$ \\
-115.024 & 37.702 & 4.7 & 1982 & 7 & 6 & $02: 10$ \\
-117.358 & 37.368 & 4.3 & 1990 & 12 & 13 & $01: 01$ \\
\hline
\end{tabular}

Table 4. Number of explosion aftershock sequences that produced an event greater than predicted at the given probability within the given duration

\begin{tabular}{llll}
\hline & \multicolumn{2}{c}{ Duration (Number of sequences with the duration) } \\
Probability & 7 days $(\mathrm{N}=93)$ & 14 days $(\mathrm{N}=72)$ & 30 days $(\mathrm{N}=36)$ \\
\hline 0.90 & $4(4.3 \%)$ & $1(1.4 \%)$ & 0 \\
0.95 & $4(4.3 \%)$ & $1(1.4 \%)$ & 0 \\
0.99 & $6(6.5 \%)$ & $1(1.4 \%)$ & 0
\end{tabular}


Table 5. Six explosions that produced an $M_{99}$ aftershock within seven days

\begin{tabular}{lllllllll}
\hline Lon & Lat & Mag & Year & Mon & Day & $\begin{array}{l}\text { Time } \\
\text { (UTC) }\end{array}$ & Name & Location \\
\hline-116.474 & 37.231 & 6.4 & 1968 & 12 & 19 & $16: 30$ & BENHAM & Pahute Mesa \\
-116.368 & 37.279 & 6.1 & 1975 & 6 & 26 & $12: 30$ & CAMEMBERT & Pahute Mesa \\
-116.412 & 37.290 & 6.3 & 1975 & 10 & 28 & $14: 30$ & KASSERI & Pahute Mesa \\
-116.333 & 37.296 & 6.3 & 1976 & 1 & 3 & $19: 15$ & MUENSTER & Pahute Mesa \\
-116.420 & 37.242 & 5.7 & 1976 & 2 & 14 & $11: 30$ & CHESHER & Pahute Mesa \\
-116.212 & 37.209 & 4.6 & 1976 & 5 & 12 & $19: 50$ & MIGHTY EPIC & Tunnel, \\
& & & & & & & & Rainier Mesa
\end{tabular}

Table 6. Number of earthquake aftershock sequences that produced less than the cumulative number of aftershocks expected at the given probability within the given duration (with $\%$ of total, $\mathrm{N}=67$ )

\begin{tabular}{llll}
\hline & & Duration \\
Probability & 7 days & 14 days & 30 days \\
\hline 0.90 & $59(88.1 \%)$ & $58(86.6 \%)$ & $60(89.6 \%)$ \\
0.95 & $59(88.1 \%)$ & $59(88.1 \%)$ & $60(89.6 \%)$ \\
0.99 & $62(92.5 \%)$ & $61(91.0 \%)$ & $62(92.5 \%)$ \\
$0.99_{\text {SoCal }}$ & $66(98.5 \%)$ & $66(98.5 \%)$ & $62(92.5 \%)$ \\
\hline
\end{tabular}

Table 7. Number of explosion aftershock sequences that produced less than the cumulative number of aftershocks expected at the given probability within the given duration

\begin{tabular}{llll}
\hline & \multicolumn{3}{c}{ Duration (Number of sequences with the duration) } \\
Probability & 2 days $(\mathrm{N}=121)$ & 7 days $(\mathrm{N}=93)$ & 30 days $(\mathrm{N}=36)$ \\
\hline 0.90 & $1(0.8 \%)$ & $1(1.1 \%)$ & 0 \\
0.95 & $2(1.7 \%)$ & $1(1.1 \%)$ & 0 \\
0.99 & $2(1.7 \%)$ & $1(1.1 \%)$ & 0 \\
$0.99_{\text {SoCal }}$ & $117(96.7 \%)$ & $91(97.9 \%)$ & $36(100 \%)$ \\
\hline
\end{tabular}


Figure 1. Background seismicity of the southern Great Basin region (black dots) with earthquakes $M>4$ (yellow stars) and nuclear test explosions (red stars on right) where the aftershock sequences analyzed in this study are given by the colored circles (referenced to Table 1) and the 'Anomaly Eq' (cyan star) and 'Anomaly Ex' are discussed in the text. The circles are examples of the aftershock region searched. The region considered in this study is given by the white box. The right panel is an enlargement of the Nevada Test Site (outlined in purple) region.

Figure 2. Little Skull Mt. (LSM) aftershock parameter calculation. a) Gutenberg-Richter distribution for calculation of magnitude of completeness $M c$ and b-value. Dashed line is the derivative of the cumulative number given by the squares. b) Modified Omori-law fit.

Figure 3. Aftershock rates and probabilities that an aftershock with magnitude $\mathrm{M} \geq \mathrm{Mm}-1$ will occur for all sequences (see Table 1) and the Median model compared with previous studies (Note: the S6 line is hidden behind the Median line).

Figure 4. Aftershock magnitude probability for all differential aftershock magnitudes (mainshock magnitude, $M m$, minus aftershock magnitude, $M$ ) as a function of time after mainshock (MS). Contours are drawn at probabilities of $0.9,0.95$, and 0.99 .

Figure 5. Aftershock model comparison with observations. a) Little Skull Mt. aftershock sequence where the gray area defines the range of differential aftershock magnitudes (mainshock magnitude, $M m$, minus aftershock magnitude, $M$ ) that have a probability of $0.99\left(M_{99}\right)$ of occurring within the first 7 days after the MS. b) BENHAM explosion aftershock sequence where the gray lines define minimum durations of 3.7, 5.2, and 10.7 days for which there is a probability of $0.90,0.95$, and 0.99 of observing an aftershock with magnitude greater than was observed 1.3 days after the MS (M4.7). c) All NTS explosion aftershock sequences. For durations greater than 32 days no AS produces an event greater than $M_{95}$ and, as shown by the gray box, for durations greater than 17 days no aftershock sequence produces an event greater than $M_{90}$. The number of aftershock sequences $\left(\mathrm{N}_{\mathrm{AS}}\right)$ as a function of duration is also shown, since the temporal windows of the explosion sequences vary based on magnitude and time to next explosion.

Figure 6. Cumulative number of aftershocks probability as a function of time after mainshock (MS) for a differential magnitude (dM) of a) 4.1 (LSM example where $M m=5.6$ and $M c=1.5$ ) and b) 3.9 (BENHAM example where $M m=6.4$ and $M c=2.5$ ). Contours are drawn at probabilities of $0.9,0.95$, and 0.99 .

Figure 7. Aftershock number model comparison with observations. a) Little Skull Mt. (LSM) aftershock sequence where the magnitude of completeness (Mc) is 1.5. b) BENHAM explosion aftershock sequence, which occurred when the Mc was 2.5.

Figure 8. Examples of anomalous aftershock sequences. a) M4.1 earthquake that occurred on 20 Dec 91 when the magnitude of completeness (Mc) was 1.5. For some durations the sequence produces less cumulative aftershocks than predicted at $\mathrm{p}=0.95\left(N_{95}\right)$. b) PONL explosion (27 Sep 85) aftershock sequence, which occurred when the Mc was 1.5. The sequence ends when the next nuclear test occurred. 
Figure 9. False classfication of a) explosions (classified as earthquake-like) and b) earthquakes (classified as anomalous). The aftershock discriminant used to calculate the percent misclassified is given by the line which is black for the aftershock number discrimiant $(\mathrm{Np})$ and gray for the aftershock magnitude discriminant $(\mathrm{Mp})$ and dashed for probability $(\mathrm{p})=0.90$ and solid for $\mathrm{p}=$ 0.99 .

Figure 10. Independent test using out of sample aftershock sequence of the Scotty's Junction earthquake (1 Aug 99). a) Aftershock magnitude model comparison with observations, where the gray lines define the durations 7.7 and 12.8 days, within which there is a probability of 0.90 and 0.95 , respectively, of observing an aftershock of magnitude equal to or greater than occurred 4.2 days after the mainshock (M3.8). The duration at a probability of 0.99 is greater than 35 days. b) Aftershock number model comparison with observations. 

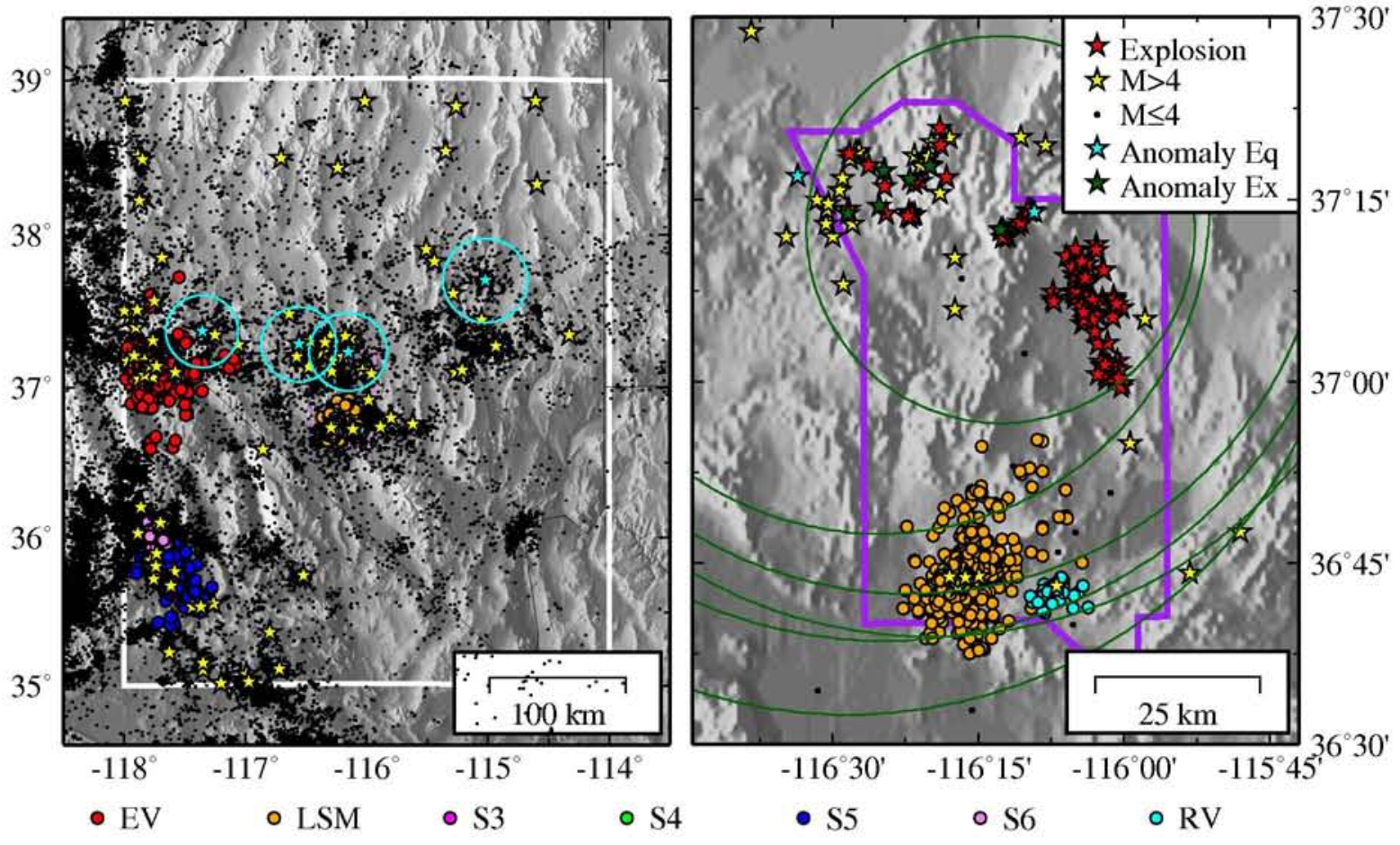

Figure 1 
a) LSM Gutenberg-Richter fit

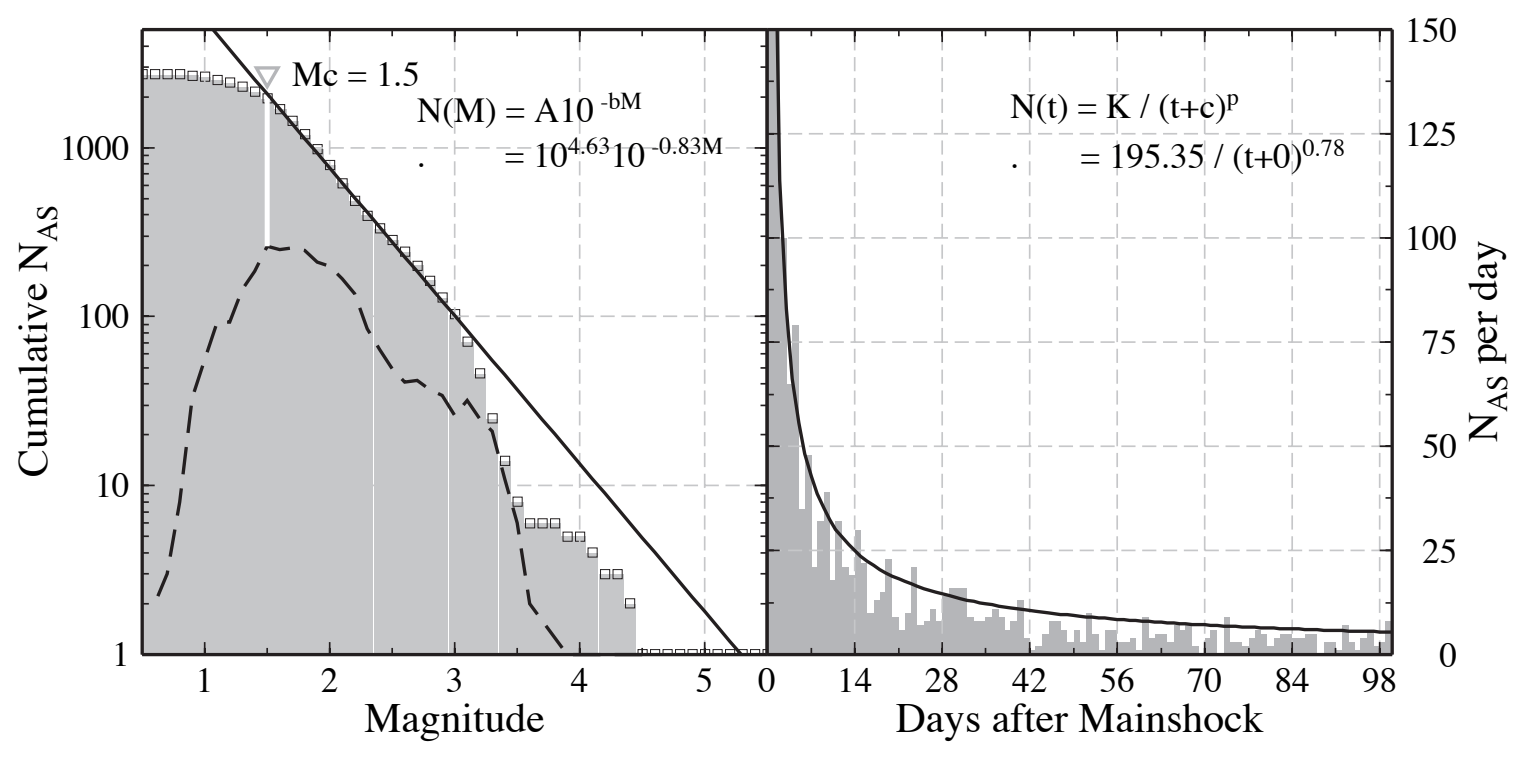

Figure 2

Ford and Walter, 2008 


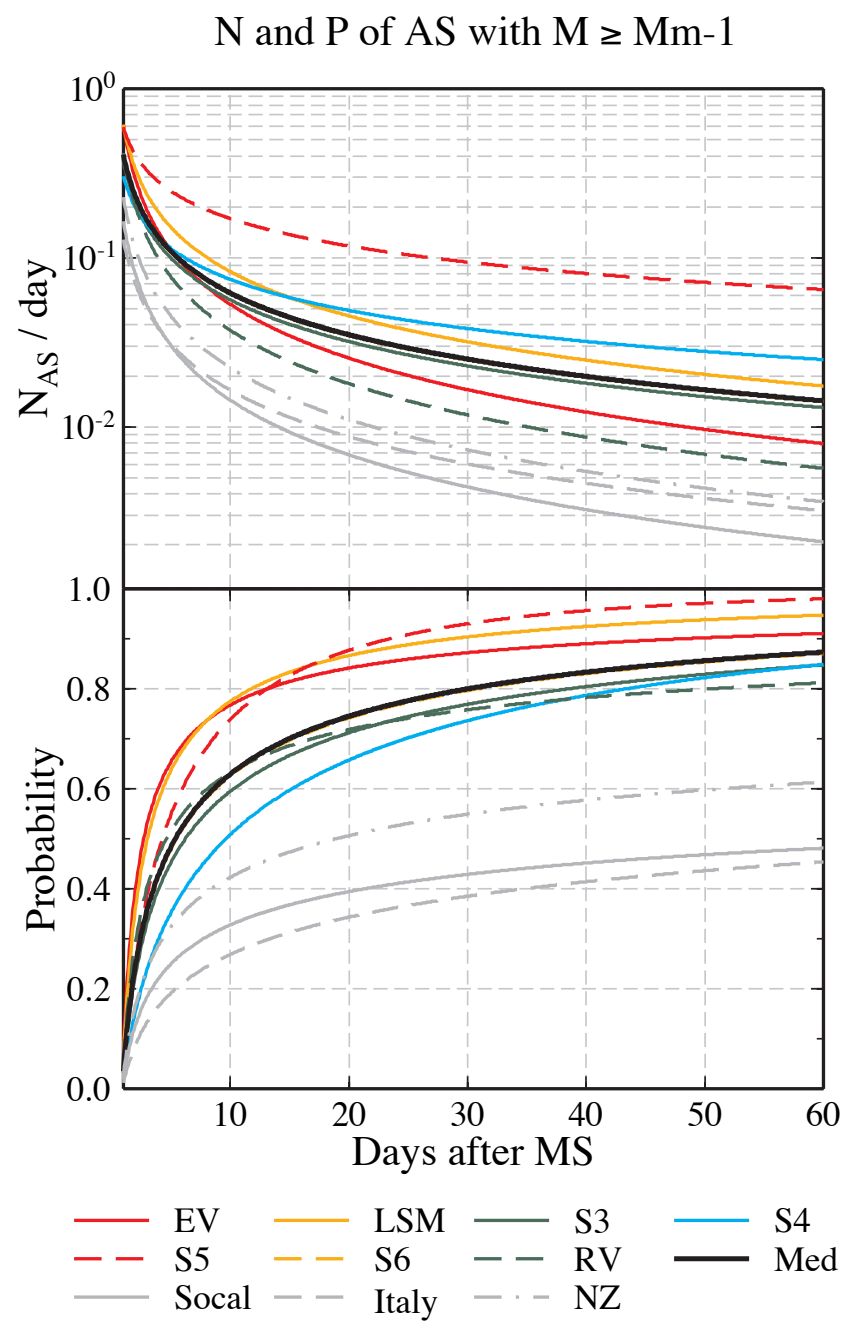

Figure 3

Ford and Walter, 2008 


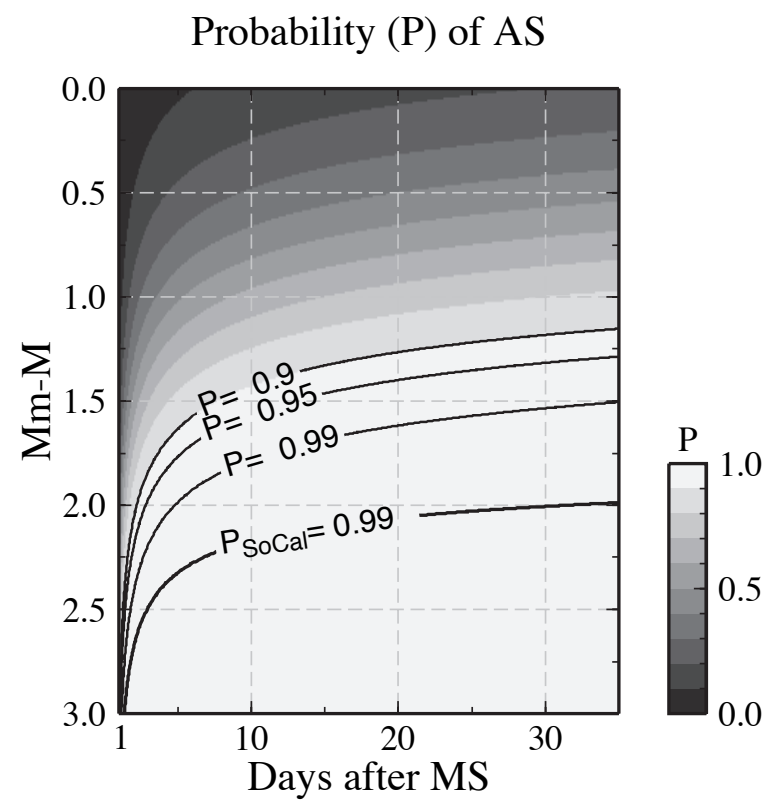

Figure 4

Ford and Walter, 2009 

a) Little Skull Mt. earthquake
b) BENHAM explosion
c) All NTS explosions

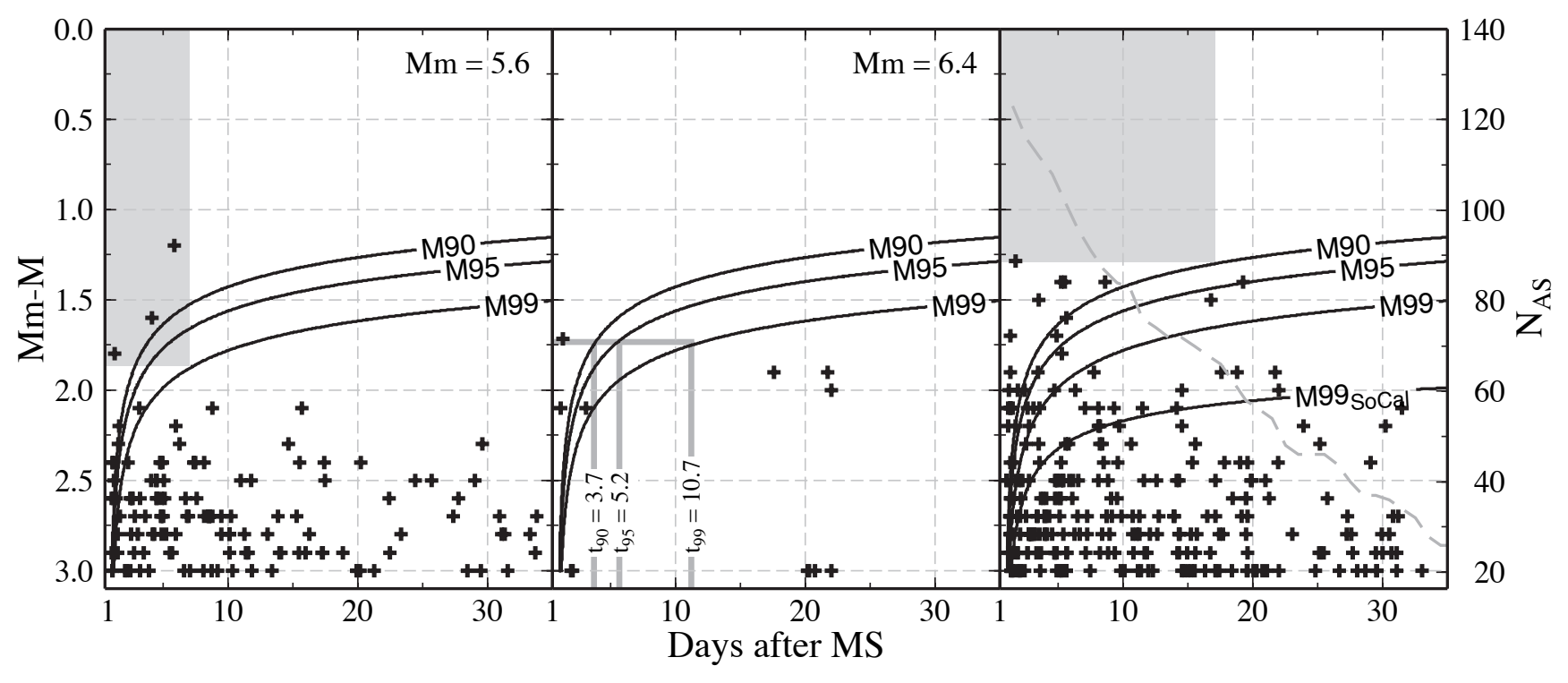

Figure 5

Ford and Walter, 2009 
a) LSM example

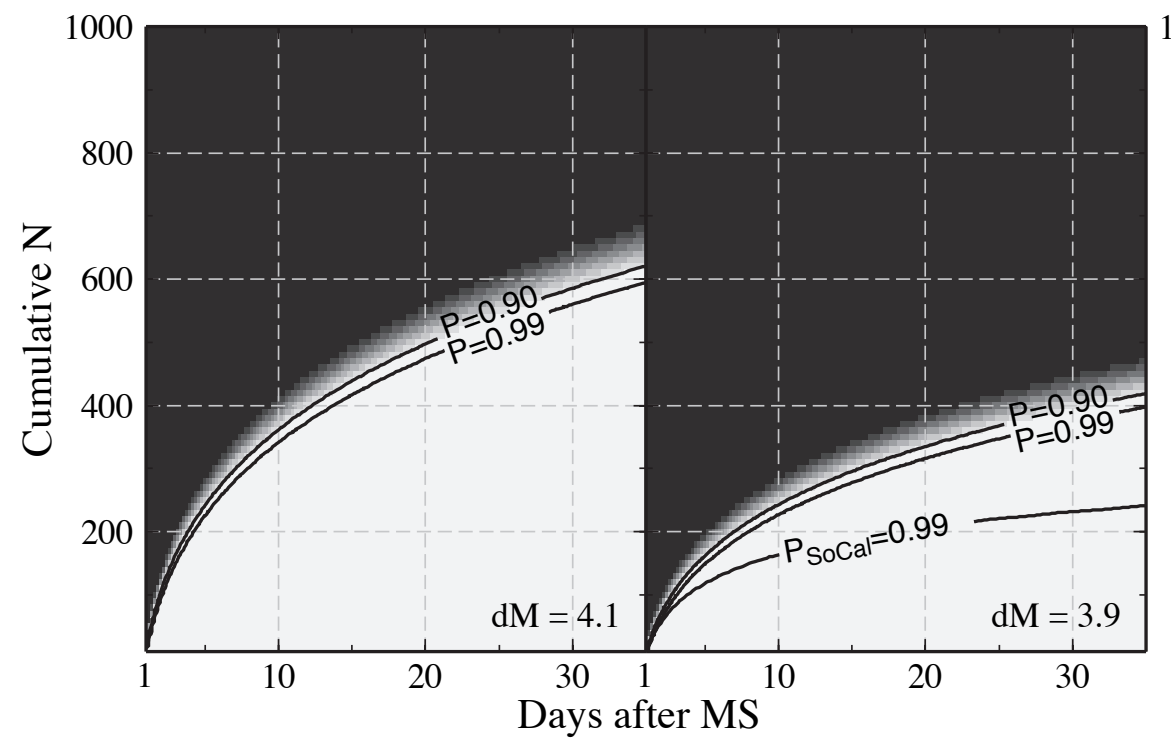

1000

800

600

400

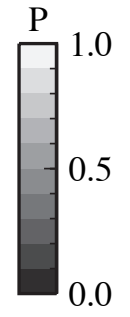

Figure 6

Ford and Walter, 2009 
a) Little Skull Mt. earthquake

b) BENHAM explosion

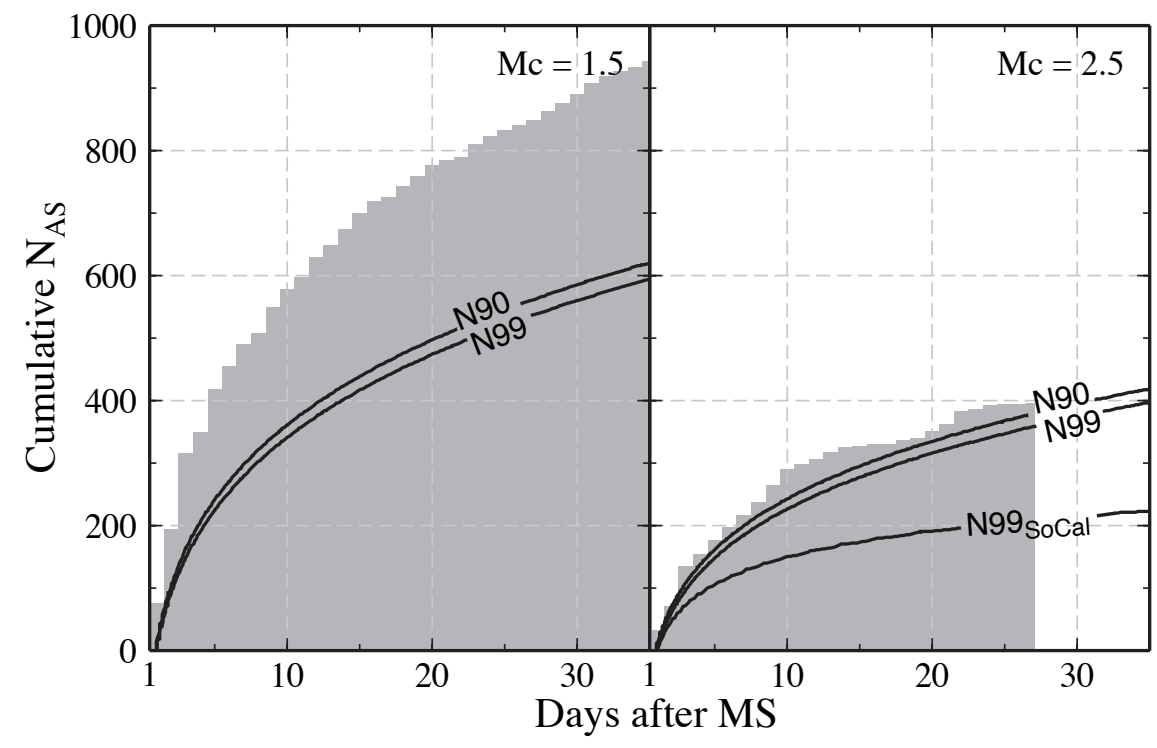

Figure 7

Ford and Walter, 2009 
$\begin{array}{lll}\text { a) EQ } 20 \text { Dec } 91 \mathrm{M} 4.1 & \text { b) EX } 27 \text { Sep } 85 \text { M4.5 (PONL) }\end{array}$

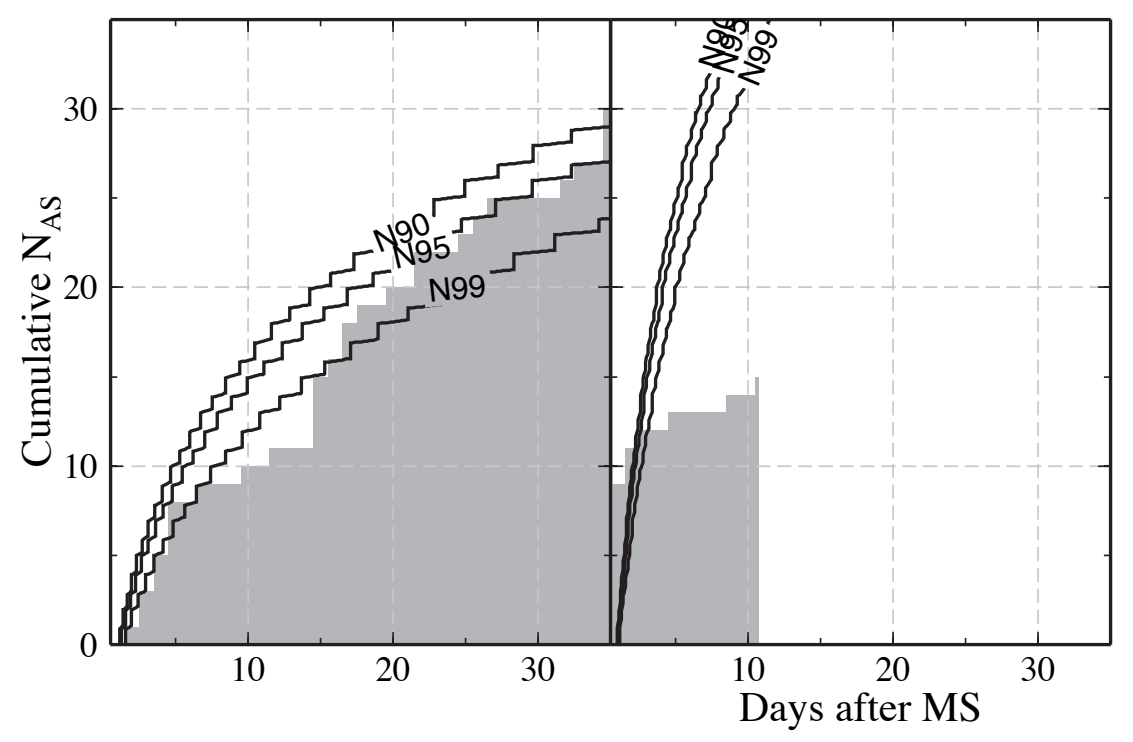

Figure 8

Ford and Walter, 2008 
False classification

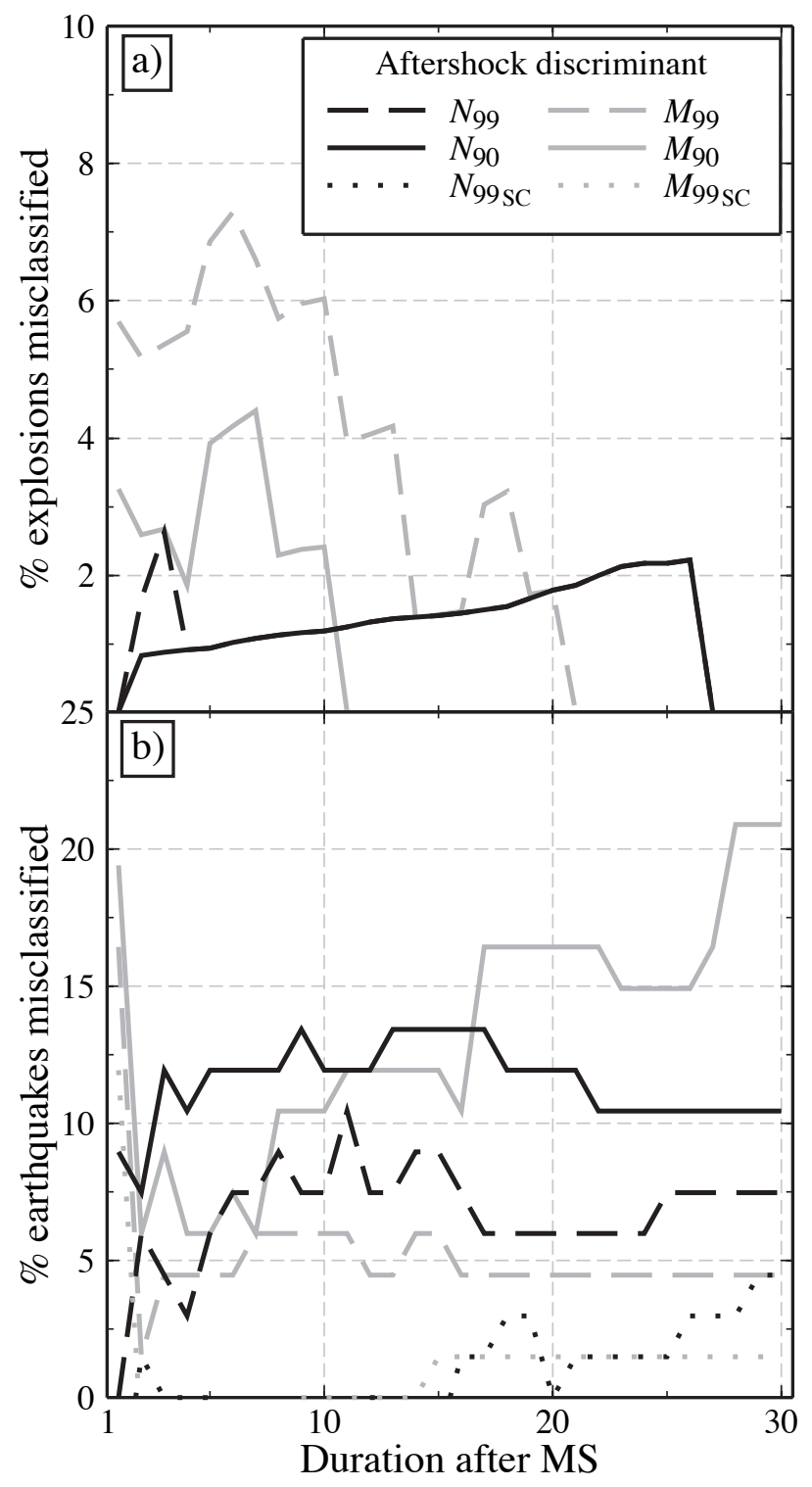

Figure 9

Ford and Walter, 2009 
Independent test (Scotty's Junction, 1 Aug 99)

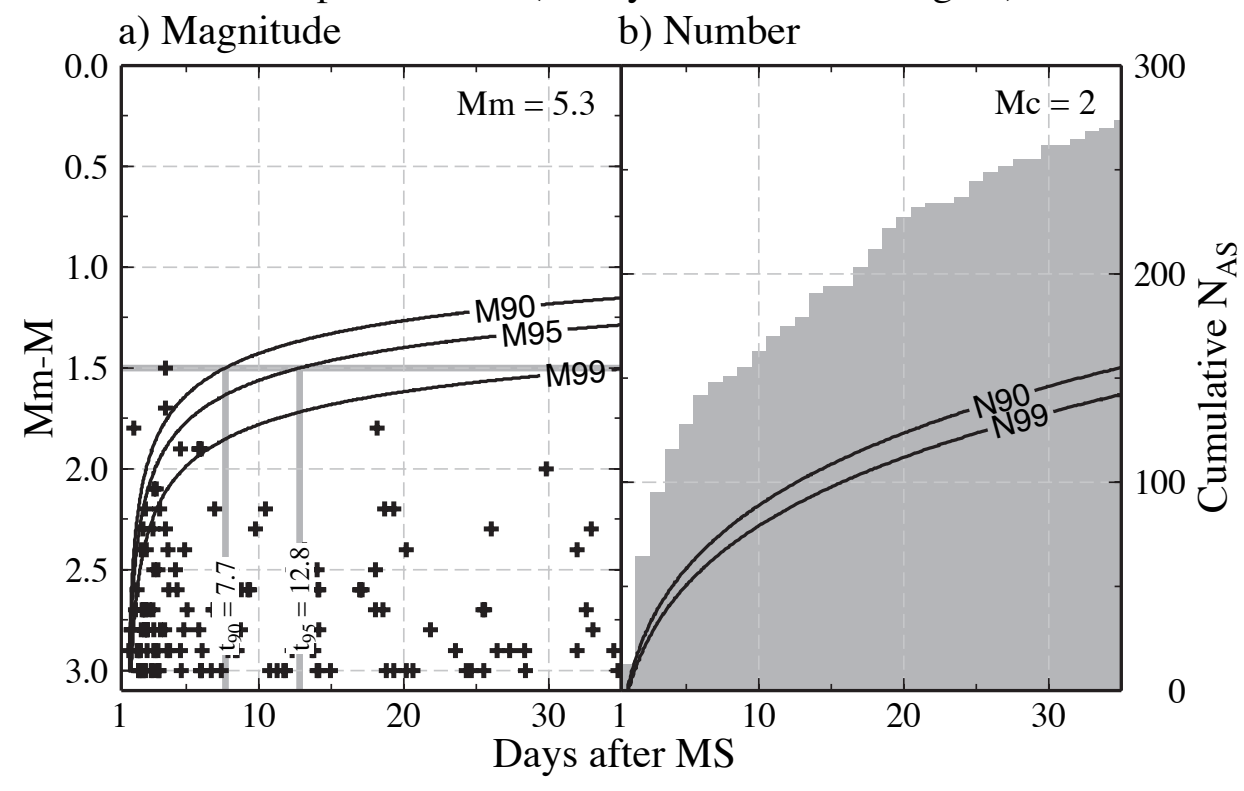

Figure 10

Ford and Walter, 2009 